\title{
ARTICLE
}

Received 17 Jul 2015 | Accepted 3 Feb 2016 | Published 9 Mar $2016 \quad$ DOl: 10.1038/ncomms10934 OPEN

\section{Editing of mouse and human immunoglobulin genes by CRISPR-Cas9 system}

Taek-Chin Cheong ${ }^{1}$, Mara Compagno ${ }^{1} \&$ Roberto Chiarle ${ }^{1,2}$

Applications of the CRISPR-Cas9 system to edit the genome have widely expanded to include DNA gene knock-out, deletions, chromosomal rearrangements, RNA editing and genome-wide screenings. Here we show the application of CRISPR-Cas9 technology to edit the mouse and human immunoglobulin (Ig) genes. By delivering Cas9 and guide-RNA (gRNA) with retro- or lenti-virus to $\operatorname{lgM}^{+}$mouse $B$ cells and hybridomas, we induce class-switch recombination (CSR) of the IgH chain to the desired subclass. Similarly, we induce CSR in all human B cell lines tested with high efficiency to targeted IgH subclass. Finally, we engineer mouse hybridomas to secrete Fab' fragments instead of the whole Ig. Our results indicate that $\mathrm{lg}$ genes in mouse and human cells can be edited to obtain any desired IgH switching helpful to study the biology of normal and lymphoma B cells. We also propose applications that could transform the technology of antibody production.

\footnotetext{
${ }^{1}$ Department of Pathology, Children's Hospital Boston and Harvard Medical School, Boston, Massachusetts 02115, USA. ${ }^{2}$ Department of Molecular Biotechnology and Health Sciences, University of Torino, Torino 10126, Italy. Correspondence and requests for materials should be addressed to R.C. (email: roberto.chiarle@childrens.harvard.edu).
} 
$\mathrm{G}$ ene rearrangements editing the immunoglobulin (Ig) genes such as $\mathrm{V}(\mathrm{D}) \mathrm{J}$ recombination and class-switch recombination (CSR) require the formation of DNA double-strand breaks (DSBs) as the key initiating step ${ }^{1-3}$. In physiological conditions, DSBs are introduced at the Ig genes by the activity of B-cell-specific enzymes such as recombinationactivating gene 1/2 (RAG1/2) and activation-induced cytidine deaminase (AID) ${ }^{1-3}$. During CSR, AID generates DSBs in the Ig locus by targeting repetitive sequences in the switch (S) regions that precede each Ig heavy (IgH) coding sequence ${ }^{1-3}$. Paired DSBs in the switch regions are then joined by the classical and alternative non-homologous end-joining (NHEJ) pathways to generate a switch of the $\mathrm{IgH}^{4}$. This long range joining is thought to be part of a general mechanism of DNA repair where two DSBs are joined in cis over long chromosome distances ${ }^{5}$. Indeed, efficient CSR can be obtained in absence of AID or S regions after the introduction of DSBs by site-specific I-SceI endonuclease ${ }^{6}$.

The bacterial type II clustered regularly interspaced short palindromic repeat (CRISPR)-Cas9 (CRISPR-associated Protein 9) systems have great potentials for RNA-guided genome editing, including multiplexing genome engineering, gene targeting by homologous recombination, regulation of transcription, chromosomal translocation formation, high-throughput functional genomic screens and even RNA editing ${ }^{7-10}$. We and others demonstrated that when two DSBs are simultaneously introduced in a cell in vitro or in vivo by CRISPR-Cas9 activity, a variety of gene rearrangements are generated, including large deletions (up to $12 \mathrm{Mb}$ ), inversions and chromosomal translocations ${ }^{11-14}$.

Here we show that the CRISPR-Cas9 system can be adapted to efficiently induce CSR in primary mouse B cells and human B-cell lines. In addition, this system can be proficiently used to engineer hybridoma cells to produce monoclonal antibody with a switched Ig heavy chain or to secrete the immunoglobulin $\mathrm{Fab}^{\prime}$ fragments only.

\section{Results}

CRISPR-Cas9-mediated CSR in mouse B cells. Since CSR is a DNA deletion induced by two DSBs occurring in the $S$ regions preceding the IgH constant sequences, we sought to engineer CSR by CRISPR-Cas9-mediated DNA deletion. We first designed a system to target the mouse $\mathrm{IgH}$ locus. Given that $\mathrm{S}$ regions are highly repetitive, we generated lentiviral vectors expressing Cas9 and guide-RNA (gRNA) targeting the more specific DNA sequences flanking immediately upstream $\left(S \mu 5^{\prime}\right.$ gRNA and $S \gamma 15^{\prime}$ gRNA) or downstream ( $S \mu 3^{\prime}$ gRNA and $S \gamma 13^{\prime}$ gRNA) of the $S$ regions that precede the mouse $C \mu$ and $C \gamma 1$ IgH constant sequences (Fig. 1a and Supplementary Fig. 1a). Efficiency of selected gRNA sequences was tested by Surveyor assay (Supplementary Fig. 1b). By introducing simultaneous DSBs in sites flanking the $S \mu$ and $S \gamma 1$ regions, the prediction was to generate deletions of the DNA segment encompassed by the two DSBs as well as excision circles in a process closely mimicking CSR occurring in $\mathrm{B}$ cells ${ }^{3}$. To test this prediction, we first transduced immortalized mouse fibroblasts. PCRs with specific primers confirmed that the expected deletions were obtained with all four gRNA combinations (Fig. 1a). Sanger sequencing of PCR products demonstrated not only the expected DNA junctions with a predominance of precise junctions between the Cas9-mediated DSBs, but also $5^{\prime}$ or $3^{\prime}$ deletions and insertions, as previously described $^{11-14}$ (Fig. 1b). PCR also detected the expected excision circles as well as inversions of the DNA segment encompassed by the DSBs, as we previously demonstrated in a different model ${ }^{13}$ (Supplementary Fig. 2a,b).

Next we sought to induce CSR in primary mouse B cells. When activated in vitro by anti-CD40 antibody and Interleukin-4 (IL-4), mouse B cells typically are induced to high levels of CSR (Supplementary Fig. 3c) ${ }^{15}$, impairing a precise assessment of CSR induced by the CRISPR-Cas9 system. Thus, we decided to exploit AID-deficient B cells in which CSR is practically undetectable ${ }^{15}$. Since retroviruses are more efficient to transduce primary B cells than lentiviruses, we generated a retroviral vector that expressed Cas9 and the same gRNAs used in fibroblasts (Supplementary Fig. 3a,b). Remarkably, with all four Cas9-gRNA combinations, we observed a small but distinct population of AID-deficient B cells that switched from IgM to $\operatorname{IgG}_{1}$ (Fig. 1c; Supplementary Fig. 3d). The overall frequency of $1 \%$ CSR was in line with previous reports describing chromosomal translocations induced by CRISPR-Cas9 (refs 11-14).

CRISPR-Cas9-mediated CSR in mouse hybridoma cells. To further validate the efficiency of the CRISPR-Cas9 system to induce CSR in mouse cells, we transduced $\operatorname{IgM}{ }^{+}$hybridoma cells. Surprisingly, higher levels of CSR than in primary B cells were observed in all hybridomas tested with all gRNA combinations (range 4-11\%; Fig. 1d,e). Remarkably, similar levels of CSR were observed when the entire $S \mu$ and $S \gamma 1$ regions were conserved $\left(\mathrm{S} \mu 3^{\prime}\right.$ gRNA with $\mathrm{S} \gamma 15^{\prime}$ gRNA) or deleted ( $\mu \mu 5^{\prime}$ gRNA with $S \gamma 1$ $3^{\prime}$ gRNA; Fig. 1a,d,e). By single-cell cloning, we isolated pure $\operatorname{IgG}_{1}$ hybridomas at the expected frequency ( 12 pure $\operatorname{IgG}_{1}$ clones out of 189 total clones: 6.3\%; Supplementary Fig. 4). Overall, these results from primary mouse $B$ cells and hybridomas showed that CSR can be achieved at high frequency by CRISPR-Cas9 system, and that hybridoma can be engineered to switch to the desired IgH subclass. Importantly, according to our strategy, CSR-edited hybridoma will retain the same V(D)J-coding sequence (Fig. 1a). Thus, this technology could be readily used to generate hybridoma with the same antigen specificity but different IgH subclass. This would represent an important application for antibody production because different $\mathrm{IgH}$ subclasses (for example, $\operatorname{IgG}_{1}$ versus $\mathrm{IgG}_{4}$ ) are known to have different affinity for the $\mathrm{Fc}$ receptor, potency in complement activation, biological properties in terms of half-life and tissue diffusion, as well different biochemical properties ${ }^{16}$.

CRISPR-Cas9-mediated CSR in human B cells. To investigate whether engineering of CSR could be efficiently achieved also in human B cells, we designed Cas9-gRNA lentiviral vectors to target the regions flanking the human $\mathrm{S} \mu$ ( $\mathrm{S} \mu 5^{\prime}$ gRNA and $\mathrm{S} \mu 3^{\prime}$ gRNA), $S \gamma 3$ (S $\gamma 33^{\prime}$ gRNA), S $\gamma 1$ (S $\gamma 13^{\prime}$ gRNA) and $S \alpha 1$ $\left(\mathrm{S} \alpha 13^{\prime}\right.$ gRNA) regions (Fig. 2a). We selected a panel of $\operatorname{IgM}^{+}$ human lymphoma cell lines that included mantle cell lymphoma (JEKO-1, GRANTA-519, UPN-1, UPN-2, MAVER-1, MINO and Z138), Burkitt lymphoma (BL-41 and BJAB) and chronic lymphocytic leukaemia (MEC-1). As shown in mouse B cells, deletion junctions were readily identified in all combinations tested and Sanger sequencing confirmed a prevalence of direct junctions over deletions and insertions (Fig. 2b; Supplementary Fig. 5). Excision circles and inversions were detected as well (Supplementary Figs 6 and 7). Remarkably, high levels of CSR were observed in each cell line tested ranging from $1 \%$ (MINO) to $60 \%$ (JEKO-1), with an average of $10 \%$ (Figs 2c and 3). The only lentivirus that did not induce CSR was $S \mu 5^{\prime}$ gRNA in Z138 cell line. When we sequenced the DNA of Z138 corresponding to the gRNA target region, we found a small deletion encompassing the $\mathrm{S} \mu 5^{\prime}$ gRNA-targeted site, thus explaining why this gRNA combination failed to induce CSR. When we transduced B lymphoma cells with three gRNAs targeting the flanking regions of $S \mu, S \gamma 1$ and $S \alpha$, we simultaneously obtained $\mathrm{IgG}_{1}^{+}$and $\mathrm{IgA}^{+}$cells from the original $\mathrm{IgM}^{+}$cells at comparable frequency (Supplementary Fig. 8). 
a

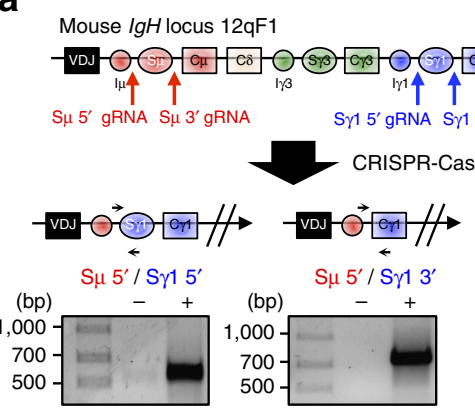

b

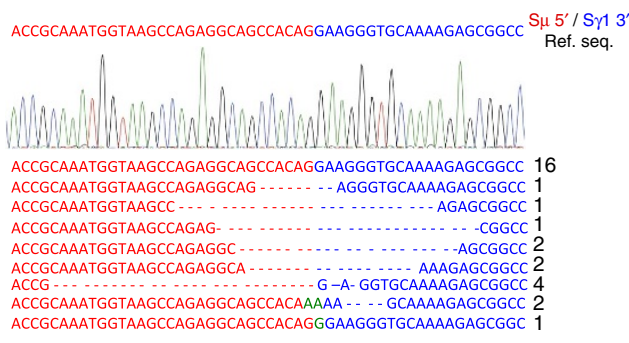

C

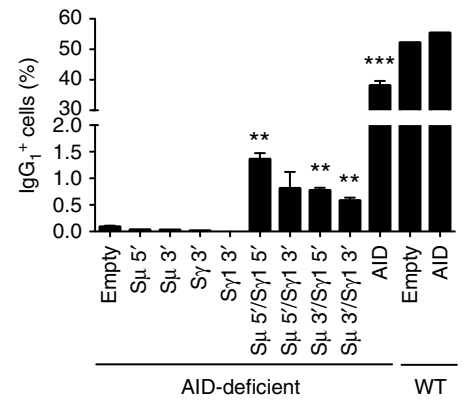

e

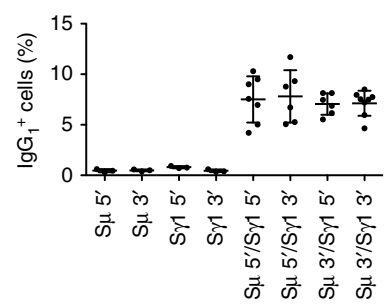

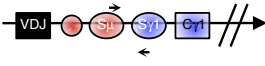
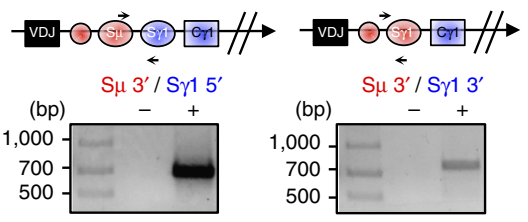

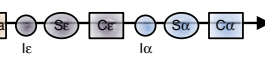

d
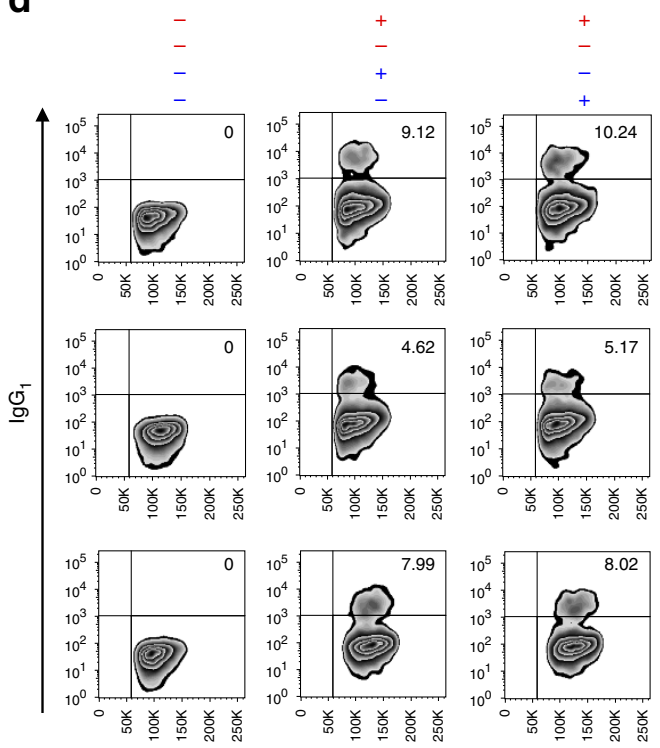
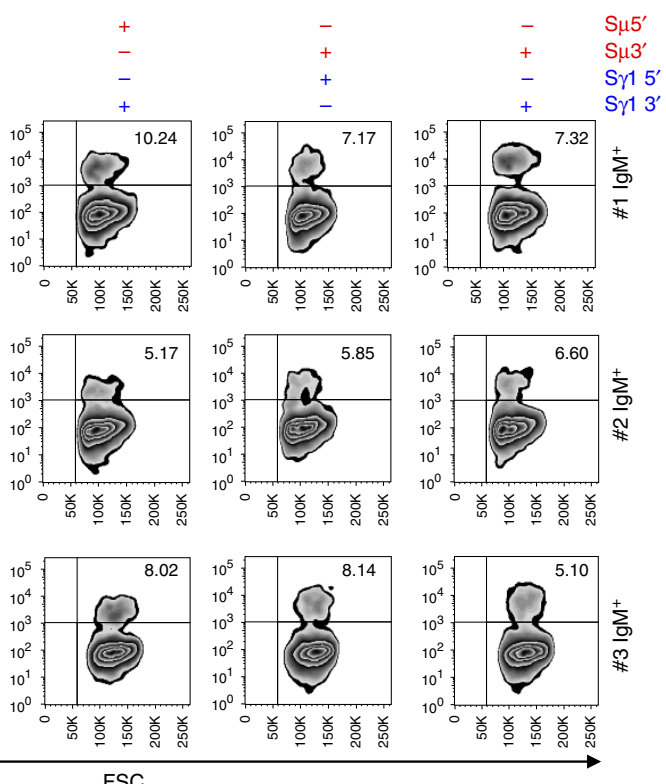
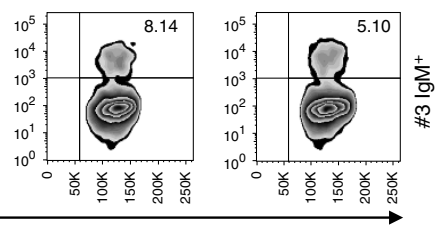

Figure 1 | Induction of class-switch recombination (CSR) by CRISPR-Cas9 system in mouse cells. (a) Top: genomic organization of the mouse IgH constant region locus and position of the gRNAs used in this study. Bottom: schematic representation of four possible CSR products induced by deletion of DNA segments between $S \mu$ and S $\gamma 1$ regions. Black arrows indicate the PCR primers designed to sequence the deletions. Gels show PCR amplicons obtained with the indicated primers. (b) An example chromatogram showing a perfect $S \mu 5^{\prime}$ and $S \gamma 13^{\prime}$ genomic junction, as well as representative sequences of junctions identified from 30 clones. Ref. Seq., sequence of the predicted genomic junction between $\mathrm{S} \mu 5^{\prime}$ and S $\gamma 13^{\prime}$ regions. Green: insertions; Dashes: deleted bases. (c) Mouse B cells isolated from the spleen of 129S2 WT and AID-deficient mice were activated by anti-CD40 antibody and IL-4 for 1 day and then transduced with retrovirus expressing Cas9 nuclease and gRNAs used in (a). Empty GFP- or AID- expressing retroviruses were used as negative or positive controls, respectively. At day 4 , cells were collected, stained with $\operatorname{lgG}_{1}$ antibody, and then analysed by flow cytometry. IgG ${ }_{1}^{+}$cells were gated on GFP-positive population. Mean \pm s.d.; $n=3$ biological replicates for each condition. Statistical analysis determined using unpaired $t$-test $(* \star P<0.01$;

$\left.{ }^{\star \star \star} P<0.001\right)$. (d,e) $\lg M^{+}$hybridomas were transduced with four different combinations of lentiviruses expressing Cas 9 nuclease and gRNAs as above. Representative zebra plots (d) and average percentages \pm s.d. of CSR (e) from six independent experiments are presented.

Next, we investigated whether human B cells could be engineered to undergo consecutive rounds of CSR, that is, whether $\mathrm{B}$ cells induced to switch first from IgM to $\operatorname{IgG}_{3}$ (or $\operatorname{IgG}_{1}$ ) were then editable to a sequential switch to IgA. Starting from $\mathrm{IgM}^{+}$JEKO-1 cells, we first induced CSR to $\mathrm{IgG}_{3}$ or $\operatorname{IgG}_{1}$ by lentiviral transduction with $S \mu 3^{\prime}$ gRNA and $S \gamma 33^{\prime}$ gRNA or $S \gamma 1$ $3^{\prime}$ gRNA and isolated pure $\mathrm{IgG}_{3}^{+}$or $\mathrm{IgG}_{1}^{+}$clones (Fig. $2 \mathrm{~d}$ and Supplementary Fig. 9). Next, we transduced $\mathrm{IgG}_{3}^{+}$or $\mathrm{IgG}_{1}^{+}$ clones with $S \mu 5^{\prime}$ gRNA and $S \alpha 13^{\prime}$ gRNA to generate new DSBs in regions flanking $S \mu$ and $S \alpha$. Remarkably, we obtained high levels of CSR to IgA, indicating that human B cells can be engineered to undergo multiple rounds of CSR at the same efficiency rate (Fig. 2d and Supplementary Fig. 9).

The high efficiency of CSR obtained in human B cell allows for potential studies on the biological role of different IgH subclass in lymphoma biology. Signalling through the B cell receptor (BCR) is required to sustain survival and proliferation of normal $B$ cells $^{17,18}$, and drugs inhibiting the BCR signalling are effective in the treatment of $\mathrm{B}$ cell lymphoma ${ }^{19}$. However, it is not clear whether different IgH subclasses that recognize the same antigen can affect lymphoma growth, possibly through a different potency or quality of the BCR signalling. The efficiency and rapidity of our CRISPR-Cas9-based method for CSR opens the possibility to address these questions. As a proof of principle, we followed over time B lymphoma cells engineered to switch to different $\operatorname{IgH}$ subclasses. First, a small fraction of lymphoma cells transduced with Cas9-gRNA lost the expression of any IgH, likely due to large deletions around the Cas9 cleavage site or to non-coding inversions or translocations. These IgH-negative cells were selectively depleted over time, indicating a growth disadvantage of B lymphoma cells that lost the BCR signalling, as expected by previous studies ${ }^{17,18}$ (Fig. 4a-d). More surprisingly, different subclasses of IgH had contrasting biological effects on lymphoma growth, as $\mathrm{IgG}_{1}^{+}$cells had a significant growth disadvantage over 
a

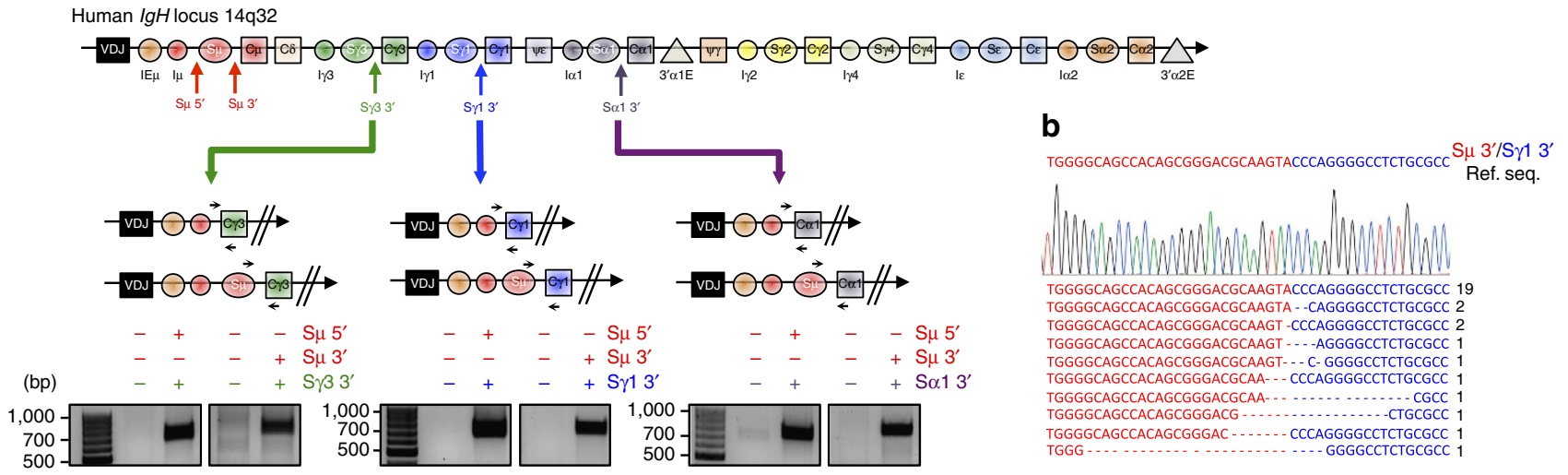

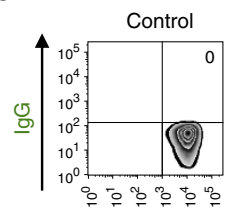
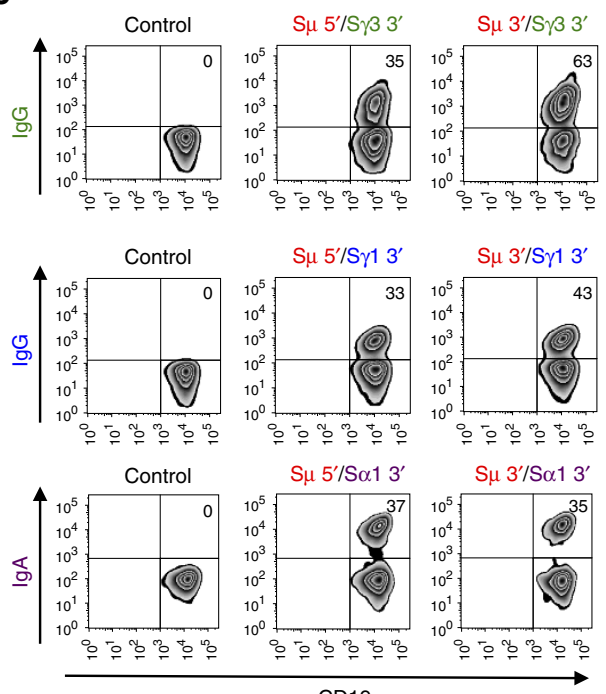

d
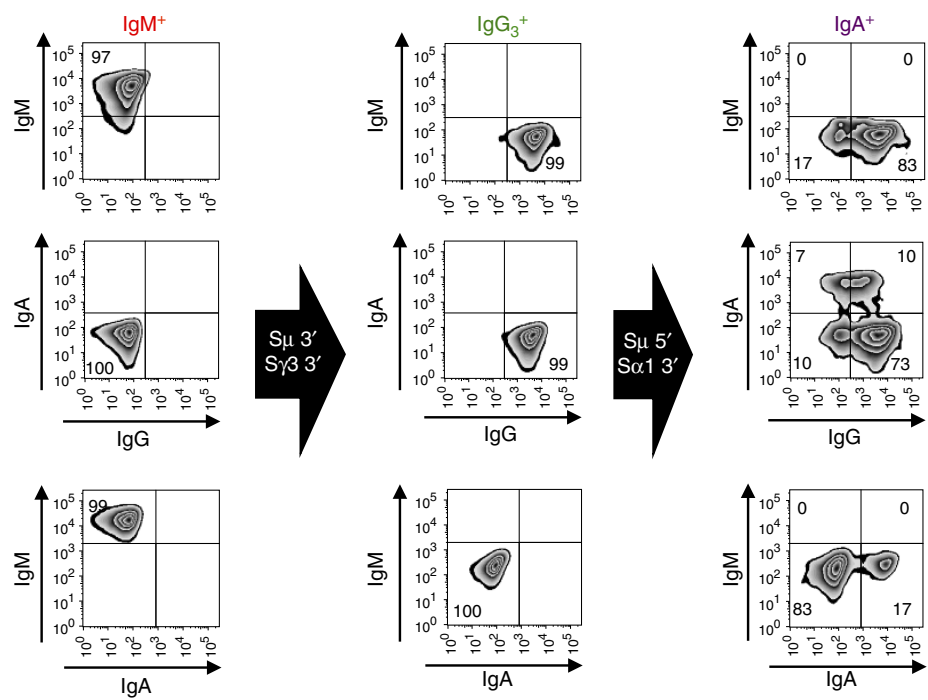

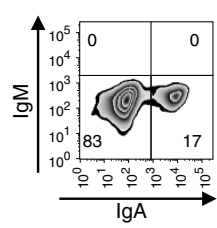

Figure 2 | Induction of CSR by CRISPR-Cas9 system in human B cell lines. (a) Top: genomic organization of the human IgH constant region locus and position of the gRNAs. Bottom: schematic representation of six possible CSR products induced by deletions between $\mathrm{S} \mu$ and $\mathrm{S} \gamma 3$, S $\gamma 1$ or $\mathrm{S} \alpha 1$ regions. Black arrows indicate the PCR primers designed to detect deletion. Gels show PCR amplicons obtained with the indicated primers. (b) Representative sequences of junctions identified from 30 clones for $S \mu 3^{\prime}$ and $S \gamma 13^{\prime}$ genomic region. Ref. Seq., sequence of the predicted genomic junction between $S \mu 3^{\prime}$ and $S \gamma 13^{\prime}$ region. Dashes: deleted bases. (c) IgM ${ }^{+}$JEKO-1 cells were transduced with lentiviruses expressing Cas9 nuclease and gRNAs targeting $\mathrm{S} \mu$ and $\mathrm{S} \gamma 3$, S $\gamma 1$ or $\mathrm{S} \alpha 1$ flanking regions. Cells were collected, co-stained with antibodies against CD19 and $\lg G$ or $\lg A$, and analysed by flow cytometry. Representative zebra plots from three independent experiments are presented. Percentages of events are indicated in the corresponding quadrants. (d) To induce sequential CSR from IgM to IgG and then to IgA, IgM ${ }^{+}$JEKO-1 cells were transduced with lentiviruses expressing Cas9 nuclease and gRNAs targeting S $\mu 3^{\prime}$ and $\mathrm{S} \gamma 33^{\prime}$ flanking regions to generate $\operatorname{lgG} 3^{+} \mathrm{JEKO}-1$ cells. $\operatorname{lgG} 3^{+}$cells were transduced again with lentiviruses expressing Cas9 nuclease and gRNAs targeting $\mathrm{S} \mu 5^{\prime}$ and $\mathrm{S} \alpha 13^{\prime}$ flanking regions. Four days later, cells were collected, co-stained with IgM, IgG, or IgA antibodies and analysed by flow cytometry. Representative zebra plots from three independent experiments are presented. Percentages of events are indicated in the corresponding quadrants.

$\mathrm{IgM}^{+}$cells, whereas $\mathrm{IgG}_{3}^{+}$or $\mathrm{IgA}^{+}$cells were positively selected (Fig. 4a-d), thus indicating that different IgH subclasses in B cell lymphoma have different biological properties.

Next, we further investigated whether loss of BCR signalling the lead to growth disadvantage in IgH-negative cells could be rescued by compensatory activation of key pathways downstream of the BCR signalling. This is an important biological concept because the BCR signalling is essential for the survival of malignant $\mathrm{B}$ cells through the activation of key downstream molecules such as the PI3K $\delta$ pathway ${ }^{18}$. To this end, we took advantage of a newly discovered point mutation $\left(\mathrm{PI} 3 \mathrm{~K} \delta^{\mathrm{E} 1021 \mathrm{~K}}\right)$ that constitutively activates PI3K $\delta$ independently of upstream BCR signalling and was recently described in patients with immunodeficiency and impaired $\operatorname{CSR}^{20,21}$. After induction of IgH loss in the JEKO-1 cell line by transduction with either $S \mu 5^{\prime} / S \gamma 33^{\prime}$ or $S \mu 3^{\prime} / S \gamma 33^{\prime}$ gRNAs, we subsequently transduced the lymphoma cells with lentivirus expressing GFP as reporter (control vector) or GFP and $\mathrm{PI} 3 \mathrm{~K} \delta^{\mathrm{E} 1021 \mathrm{~K}}$. IgH-negative lymphoma expressing GFP were progressively depleted with similar kinetics to untransduced cells. In contrast, IgH-negative lymphoma cells expressing $\mathrm{PI} 3 \mathrm{~K} \delta^{\mathrm{E} 1021 \mathrm{~K}}$ were significantly rescued as compared to $\mathrm{GFP}^{-}$or $\mathrm{GFP}^{+}$control cells (Fig. 4e).

Generation of Fab' fragment-secreting hybridomas. Finally, the high efficiency of CRISPR-Cas9 system to edit the IgH locus prompted us to further investigate possible applications in antibody production. For several experimental or clinical applications, $\mathrm{Fab}^{\prime}$ fragments are preferable to whole antibodies. To obtain $\mathrm{Fab}^{\prime}$ fragments, purified antibodies are often processed by enzymatic digestion with proteases, such as papain or pepsin, followed by further purification to remove the Fc binding portion 


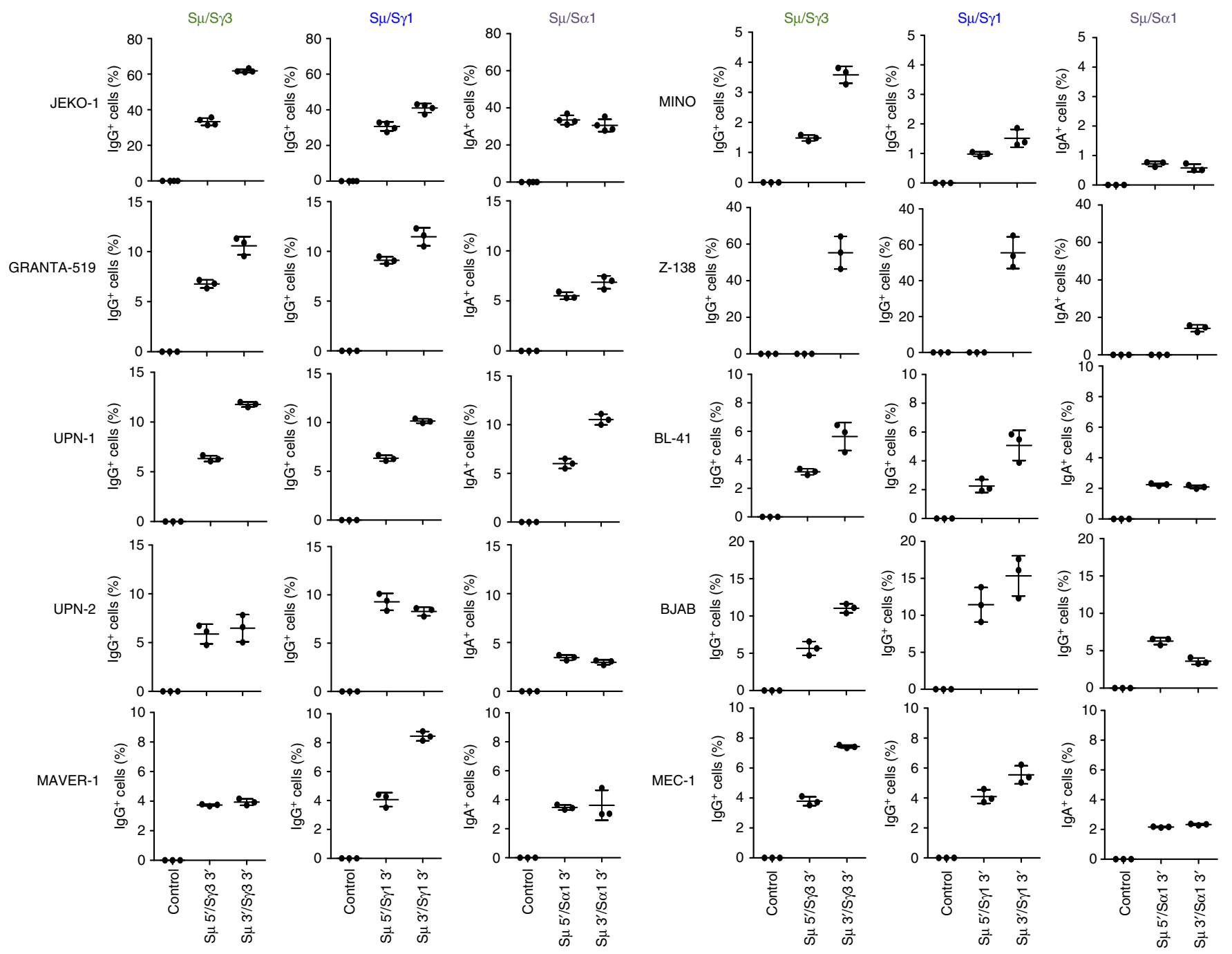

Figure 3 | CSR in a panel of human B-cell lymphoma lines. Ten different human B-cell lymphoma lines (JEKO-1, GRANTA-519, UPN-1, UPN-2, MAVER-1, MINO, Z-138, BL-41, BJAB and MEC-1) were transduced with lentiviruses expressing Cas9 nuclease and gRNAs targeting S $\mu$ and S $\gamma 3$, S $\gamma 1$, or S $\alpha 1$ flanking regions. Two days later, cell lines were selected with puromycin $\left(0.2 \mu \mathrm{g} \mathrm{ml} \mathrm{m}^{-1}\right)$ for 3 days. Live cells were collected, co-stained with CD19 and IgG or IgA antibodies, and analysed by flow cytometry. As a control, non-transduced or single lentivirus-transduced cells were used. Data were analysed by FlowJo software. Mean \pm s.d.; $n=3$ biological replicates for each condition.

and to maintain the antigen-specific binding portion $\left(\mathrm{Fab}^{\prime}\right.$ fragment $)^{22}$. We reasoned that we could produce $\mathrm{Fab}^{\prime}$ fragments directly in hybridoma cells by deleting the Fc-coding sequence of the IgH chain. To obtain the Fc portion deletion, we designed gRNAs targeting the DNA proximal to the papain cleavage site of the $\operatorname{IgG}_{1}$ coding sequence. We tested either a frameshift approach where the deletion of the Fc portion is achieved by an out-offrame NHEJ-mediated repair of the DSB introduced by Cas9 (Fc $5^{\prime}$ ) or a complete deletion approach where the DNA sequence for the $\mathrm{Fc}$ portion is deleted by two flanking DSBs $\left(\mathrm{Fc} 5^{\prime}\right.$ and $\left.\mathrm{Fc} 3^{\prime}\right)$ (Fig. 5a). As a consequence of this deletion, the hybridoma should become IgH-negative because of the loss of the IgH membranebinding domain ${ }^{23}$. Indeed, by either approach, we observed a high percentage of $\operatorname{IgG}_{1}$-negative cells (Fig. 5b,c), likely indicating an efficient deletion of the $\mathrm{Fc}$ fragment. To compare the relative efficiency of the two approaches we isolated single clones from a hybridoma co-transduced with $\mathrm{Fc} 5^{\prime}$ and $\mathrm{Fc} 3^{\prime}$. Out of the 64 isolated single-cell clones, only 4 (6.2\%) deleted the Fc-coding sequence of the IgH chain, whereas in the majority of the clones the loss of the $\mathrm{Fc}$ coding was mediated by frameshift (Supplementary Figs 10 and 11). Next, we expanded $\operatorname{IgG}_{1^{-}}$ negative clones (Supplementary Fig. 12) and tested for production of $\mathrm{Fab}^{\prime}$ fragments. We collected hybridoma supernatants and separated the proteins on a SDS-PAGE gel in non-reducing conditions. By western blot assay with an anti-kappa-light chain antibody, $\mathrm{IgG}_{1}$-negative engineered hybridomas secreted $\mathrm{Fab}^{\prime}$ fragments together with the expected kappa-light chain $^{24}$, whereas control $\operatorname{IgG}_{1}^{+}$hybridomas secreted the whole $\mathrm{IgG}_{1}$ as expected (Fig. 5d,e). As predicted, both the $\mathrm{Fab}^{\prime}$ fragments and the whole $\operatorname{IgG}_{1}$ completely disappeared when the SDS-PAGE gel was run in reducing conditions (Supplementary Fig. 13). Thus, hybridomas producing $\mathrm{Fab}^{\prime}$ fragments can be generated rapidly and effectively by CRISPR-Cas9 technology.

\section{Discussion}

Altogether our data demonstrate the feasibility of a fast and efficient editing the Ig genes in human and mouse B cells by CRISPR-Cas9 technology. CSR was induced with equal efficiency whether the gRNAs were directed to target sequences upstream or downstream the switch regions, as predicted by the current models of $\operatorname{CSR}^{1,25}$. Consistent with the notion that CSR is a 

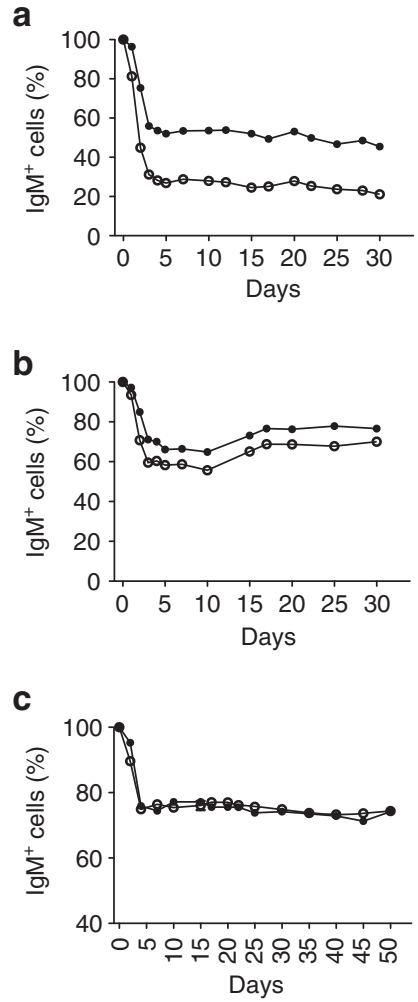

d

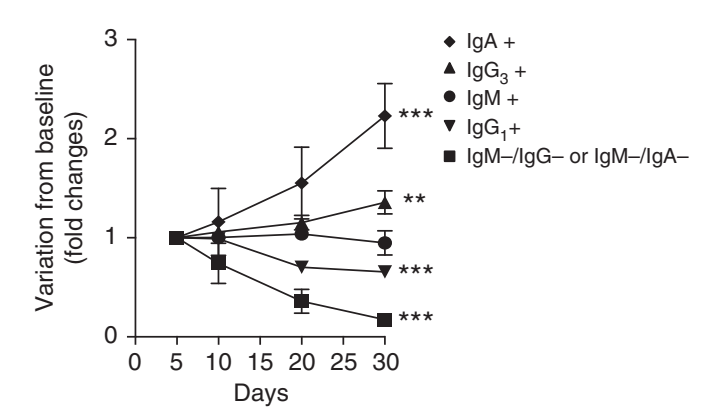

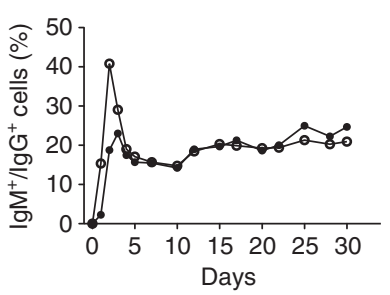
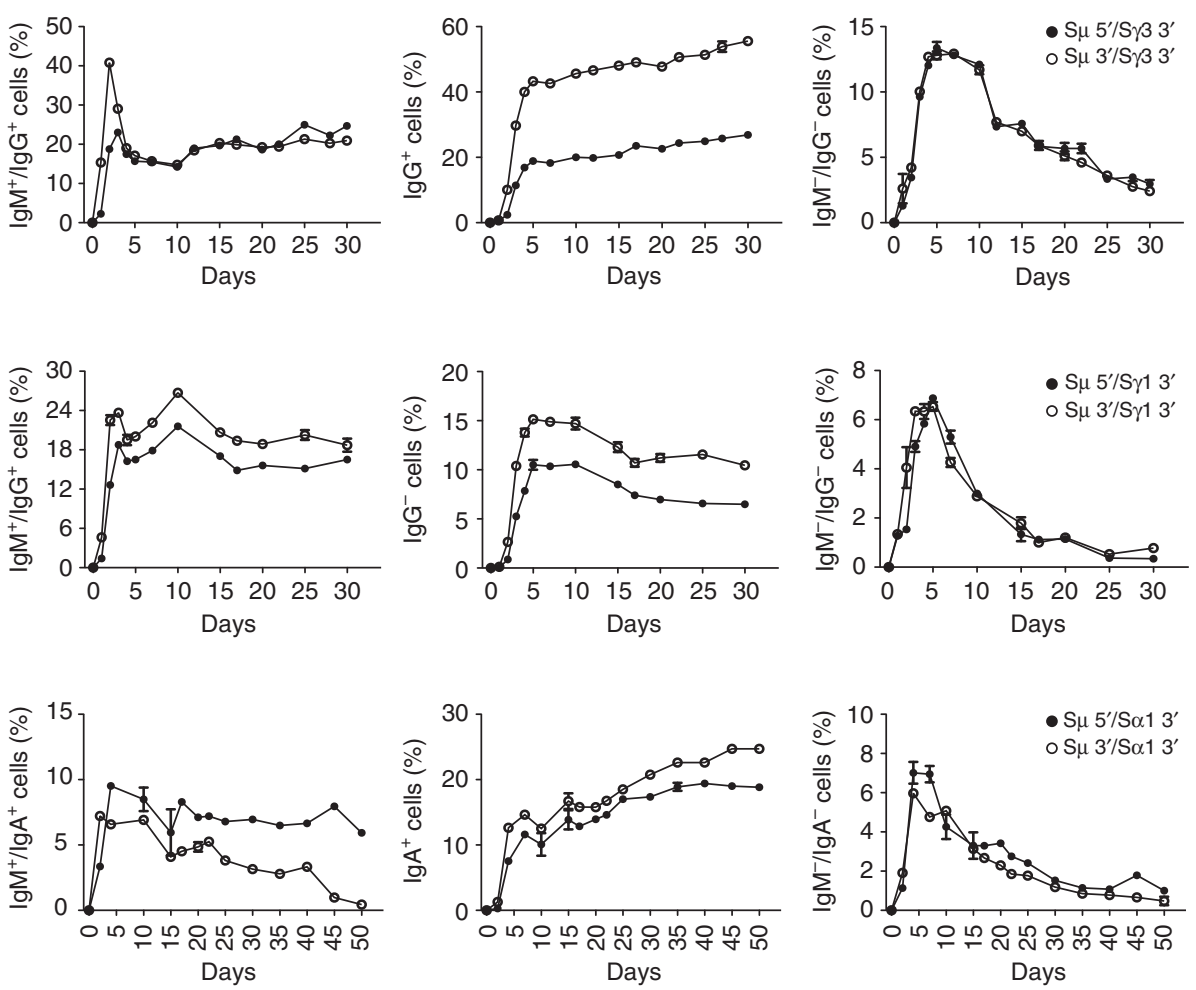

e

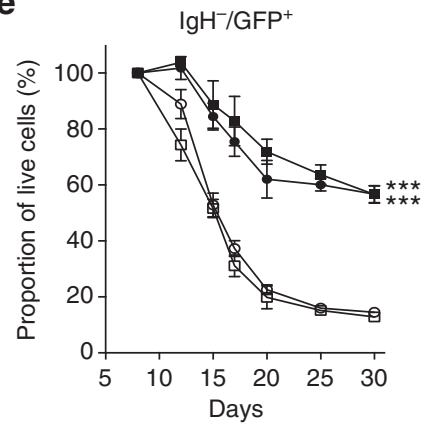

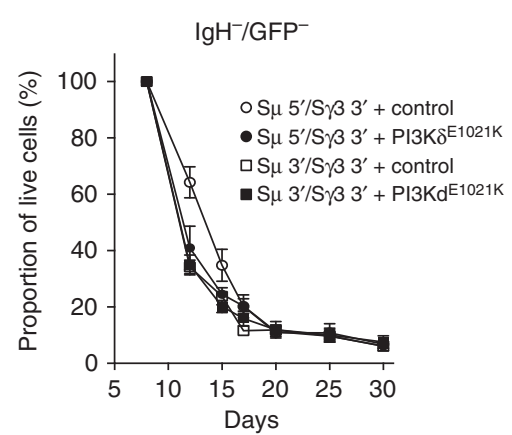

Figure 4 | Biological effects of IgH subclass switch in human lymphoma cell growth. (a-c) To understand the growth of $B$ cells after switch of the IgH subclass, JEKO-1 cells were co-transduced with two lentiviruses expressing Cas9 nuclease and gRNAs targeting $S \mu$, S $\gamma 3$ 3' (a), S $\gamma 1$ 3' (b) and S $\alpha 13^{\prime}$ (c) flanking regions. Cells were co-stained with antibodies against $\lg M$ and $\operatorname{lgG}$ or $\lg A$ and analysed by flow cytometry over time. (d) Statistical analysis of relative growth rates from lymphoma cells from Fig. $4 a-c$. Data are from at least four experiments in each condition. $P$ values are calculated for each IgH subclass compared with native lgM ${ }^{+}$cells. Data are expressed as mean \pm s.d. for four independent experiments. Statistical analysis determined using twoway ANOVA $\left({ }^{\star \star} P<0.01 ;{ }^{\star \star \star} P<0.001\right)$. (e) JEKO-1 cells were transduced with lentiviruses expressing Cas 9 nuclease and gRNAs targeting S $\mu$ and $\mathrm{S} \gamma 3$ regions. After 5 days, cells were transduced with retroviral vector expressing PI3K $\delta^{\mathrm{E} 1021 \mathrm{~K}}$ or control vector. Cells were co-stained with antibodies against $\operatorname{lgM}$ and $\operatorname{lgG}$ to allow the gating on the $\mathrm{lgH}$-negative population $\left(\mathrm{IgH}^{-}=\lg \mathrm{M}^{-} / \mathrm{lgG} \mathrm{g}^{-}\right)$and percentages of $\mathrm{GFP}^{+}$cells were analysed over time by flow cytometry. As additional control $\mathrm{IgH}^{-}$cells not transduced with the retrovirus ( $\mathrm{GFP}^{-}$) were analysed. Data are from two independent experiments each repeated in duplicates and are expressed as mean \pm s.d. Statistical analysis determined using two-way ANOVA $\left({ }^{\star \star \star} P<0.001\right)$.

peculiar form of gene rearrangement in the $\mathrm{IgH}$ locus, when we introduced two gRNAs in the cells we found additional genomic rearrangements, such as inversions and interchromosomal translocations as we and others previously described with CRISPR-Cas9 technology ${ }^{11-14}$. The predominance of precise junctions between the two DSBs generated by Cas9 reflects the described property of Cas9 to generate blunt ends 3 bp upstream of the PAM sequence ${ }^{26}$. Blunt ends are then joined by the c-NHEJ pathway, which could also be responsible for small deletions or insertions ${ }^{4}$.

Efficiency of CSR was remarkably high in hybridoma and human B lymphoma cells. This was quite surprising but consistent with the observations made by our group and others that rearrangements occur with high frequency between two DSBs that occur at a low genomic distance on the same chromosome ${ }^{5,15,27,28}$. The lower CSR achieved in primary mouse B cells was likely due to a lower efficiency of transduction than hybridomas and human B cells. Currently used lentiviral or retroviral CRISPR-Cas9 vectors produce relatively low viral titres due to the large size of the constructs ${ }^{29}$. The recent demonstration that smaller Cas 9 molecules obtained by Staphylococcus aureus have similar efficiency to Streptococcus pyogenes (SpCas9) allows the design of smaller retroviral constructs that should generate more efficient viruses ${ }^{30}$. In addition, the cloning of two gRNAs in the same vector instead of two independent vectors should further increase the efficiency of CSR by increasing the number of cells co-expressing the two gRNAs. 
a

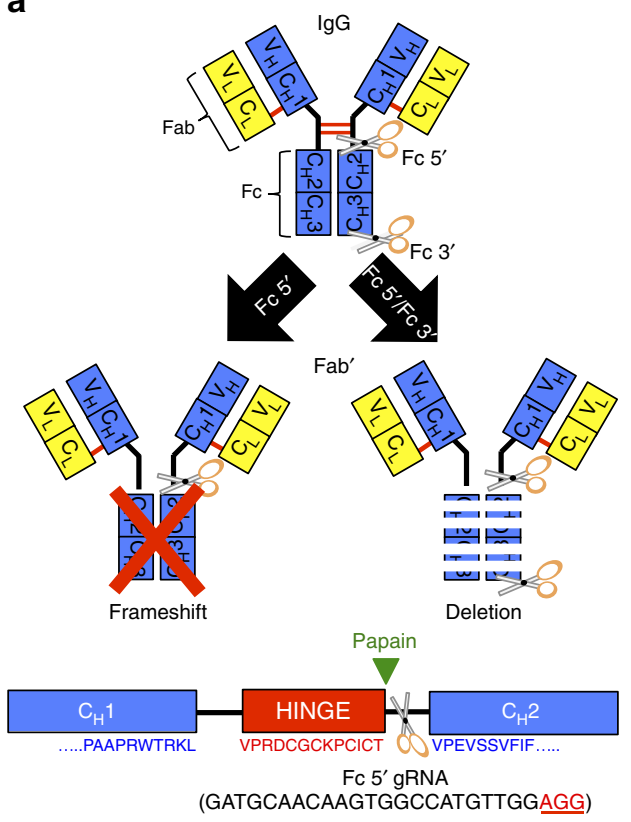

b

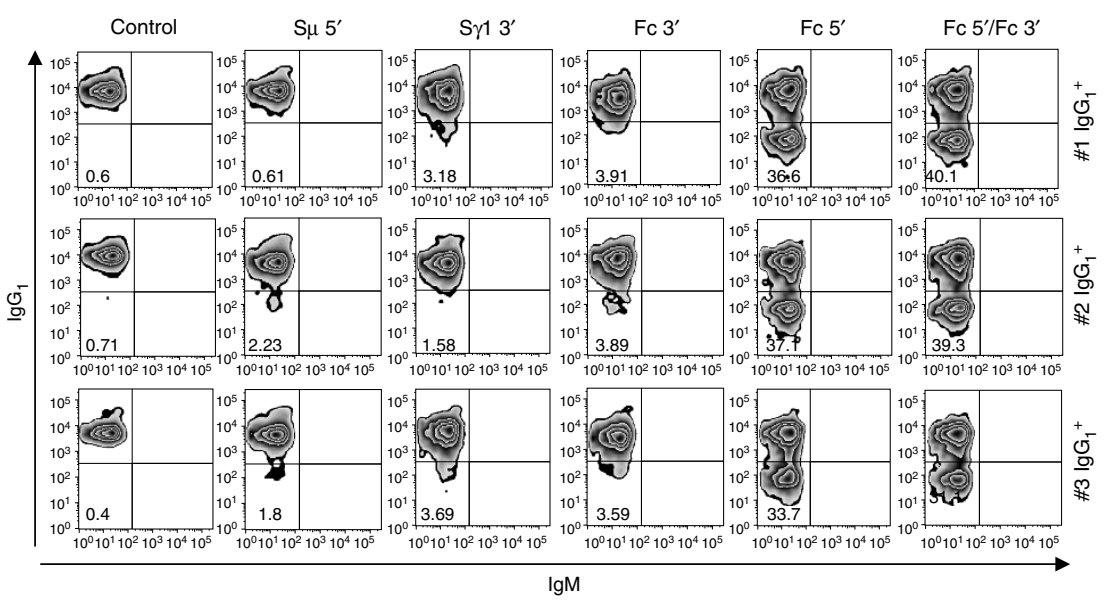

C

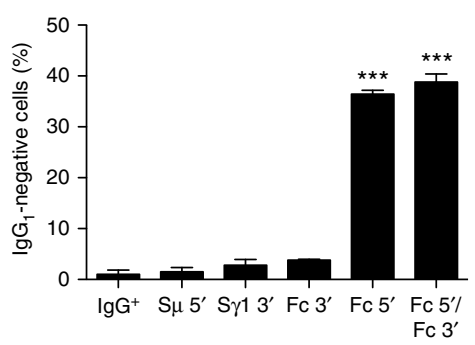

d

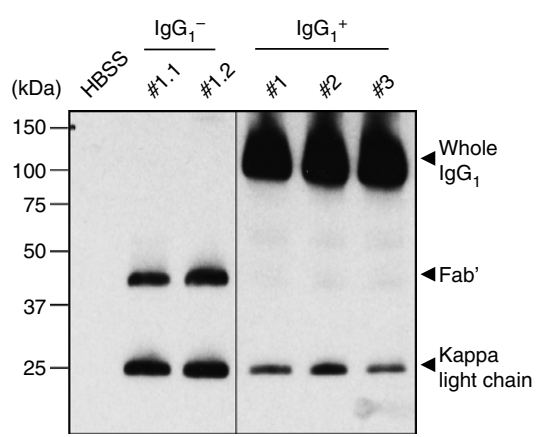

e

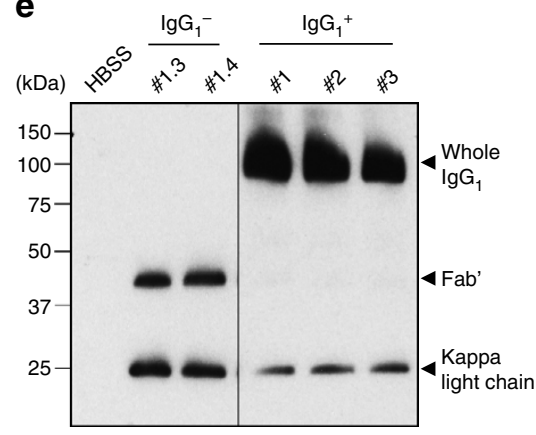

Figure 5 | Generation of Fab' fragments by CRISPR-Cas9 system in mouse hybridomas. (a) Top: schematic representation of mouse IgG antibody and target sites of two different gRNAs used for Fab' fragment production. By using lentiviruses expressing Cas 9 nuclease and Fc $5^{\prime}$ or Fc $5^{\prime} / F c 3^{\prime}$ guide RNAs, $\mathrm{Fab}^{\prime}$ fragments were produced by frameshift (left) or deletion (right) of the IgH Fc fragment, respectively. Bottom: schematic depiction of $5^{\prime}$ gRNA (scissors) in reference to the papain cleavage site. PAM sequence is underlined in red text. (b) $\operatorname{lgG}_{1}^{+}$hybridomas were transduced with lentivirus expressing Cas 9 nuclease and gRNAs targeting Fc $5^{\prime}$ or Fc $5^{\prime}$ and Fc $3^{\prime}$ regions. gRNAs targeting S $\mu 5^{\prime}, S_{\gamma} 13^{\prime}$ or Fc $3^{\prime}$ were used as negative controls. Hybridomas were selected with puromycin, stained with $\lg M$ and $\lg G_{1}$ antibodies, and analysed by flow cytometry. Representative zebra plots from three different $\operatorname{lgG}_{1}^{+}$hybridomas are presented. Percentages of events are indicated in the corresponding quadrants. (c) Histograms representing the percentages of lgG-negative cells are shown with mean \pm s.d.; $n=3$ biological replicates for each condition. Statistical analysis determined using unpaired $t$-test $\left({ }^{\star \star \star} P<0.001\right)$. (d,e) Western blot analyses of Fab' fragments from hybridoma supernatants. $\mathrm{IgG}_{1}^{+}$hybridomas were transduced with lentiviruses expressing Cas 9 nuclease and gRNAs targeting $\mathrm{Fc} 5^{\prime}$ or $\mathrm{Fc}^{\prime}{ }^{\prime}$ and $\mathrm{Fc}^{\prime}{ }^{\prime}$ regions and IgG $\mathrm{G}_{1}$-negative single clones were obtained by serial dilution. Examples of two clones from the frameshift approach (d; \#1.1 and \#1.2; purity $>99 \%)$ and two clones from the deletion approach (e; \#1.3 and \#1.4; purity >99\%) are shown. Supernatants were loaded on a SDS-PAGE in non-reducing condition, and developed with an anti-mouse kappa-light chain antibody. Three different $\operatorname{lgG}_{1}^{+}$hybridomas were used as controls.

CRISPR-Cas9-mediated CSR in hybridoma cells was efficient, fast and easy allowing for CSR to any desired $\operatorname{IgH}$ subclass. Implication for the technology of antibody production could be profound. For example, IgG antibodies are preferred for applications such as western blot analysis, immunohistochemistry and ELISA, whereas IgM clones are typically discarded because IgM are pentameric, more difficult to purify and less stable than IgG. In addition, different IgG subclasses have different stability, as well as biological and biochemical properties. For examples, effector functions in terms of triggering Fc $\gamma \mathrm{R}$-expressing cells, activating complement, phagocytosis or antibody-dependent cell-mediated cytotoxicity are different within $\operatorname{IgG}_{1}, \mathrm{IgG}_{2}, \mathrm{IgG}_{3}$ and $\mathrm{IgG}_{4}$ subclasses ${ }^{30}$. By applying the approach we propose, it would be possible to easily switch hybridomas to the desired
IgH subclass for any laboratory or therapeutic use. In addition, we have also shown that hybridoma can be engineered to produce $\mathrm{Fab}^{\prime}$ fragments instead of the corresponding whole $\mathrm{IgH}$ molecule. $\mathrm{Fab}^{\prime}$ fragments were directly produced and secreted by hybridoma cells in culture at comparable levels to the unedited whole $\operatorname{IgH}$ molecules. This approach would largely simplify the method for the production of Fab' fragments that is currently based on several steps of protease cleavage followed by purification of the resulting fragments. We propose that engineering hybridomas to directly produce Fab' fragments will represent an important advancement given that $\mathrm{Fab}^{\prime}$ fragments are preferred for several experimental approaches as well as for therapeutic deliver of more effective antibody-drug conjugates $^{31}$. 
Finally, CSR was achieved in human B cells at high efficiency, a feat never accomplished so far. In contrast to primary mouse $B$ cells, induction of CSR in human B cells is largely inefficient with current methods ${ }^{32}$. In contrast, by CRISPR-Cas9 technology we were able to rapidly and efficiently induce CSR in all human B-cell lines tested to any desired IgH subclass. We propose that Cas9mediated editing provides a highly useful approach for the study of the functional activity of different IgH subclass in the physiology and pathology of human B cells as the contribution of the different IgH subclasses is largely unknown. Furthermore, unveiling the network of signalling pathways initiated by the BCR has become increasingly important to understand the physiology of normal $\mathrm{B}$ cells $^{17}$ as well as the pathological survival and expansion of neoplastic $\mathrm{B}$ cells ${ }^{19}$. Indeed, inhibition of BCR activity has recently changed the treatment landscape for B-cell malignancies ${ }^{33-38}$. Inhibitors of key molecules in BCR signalling such as $\mathrm{PI} 3 \mathrm{~K} \delta$ inhibitors (idelalisib) or Bruton tyrosine kinase-BTK inhibitors (ibrutinib) have been recently approved by the FDA for the treatment of CLL or $\mathrm{MCL}^{39}$ and others are under investigation ${ }^{40}$. As we showed in reconstitution experiments with activated PI3K $\delta$ constructs, modelling CSR or eliminating BCR signalling by CRISPR-Cas9 technology will provide opportunities to precisely reconstruct the contribution of single pathways or molecules to the biology of normal and neoplastic B cells.

\section{Methods}

Animals. Female 129/SvJ, 129S2 and AID-deficient mice at 8-12 weeks of age were used in the experiments. A minimum of three mice for each experiment was used. No exclusion criteria were used. 129S2 mice (Charles River) and AID-deficient mice, which were kindly provided by Dr Frederick W. Alt (Boston Children's Hospital), were housed and maintained in the specific pathogen free (SPF) facility at Boston Children's Hospital. Animal experiments were performed under protocol approved by the Institutional Animal Care and Use Committee (IACUC) of Boston Children's Hospital (Protocol \#13-01-2295).

Plasmid DNA constructions. For SpCas9 expression and generation of guide-RNA (gRNA), the 20-nucleotide target sequences were selected to precede a $5^{\prime}$-NGG protospacer-adjacent motif (PAM) sequence. To minimize off-target effects, the CRISPR design tool from Dr Feng Zhang laboratory was used (http://crispr.mit.edu/). All gRNA and PAM sequences used in this study are listed in Supplementary Table 1. Oligonucleotides were purchased from Integrated DNA technology (IDT), annealed and cloned into the BsmBI-BsmBI sites downstream from the human U6 promoter in LentiCRISPR v2 plasmid, which was a gift from Dr Feng Zhang (Addgene plasmid \#52961). Oligonucleotides used in this study for cloning are listed in Supplementary Table 2.

To generate RetroCRISPR v1 plasmid, all gRNAs were first cloned in LentiCRISPR v2 vector. To obtain retroviral backbone, pMSCVgfp::AID plasmid, a gift from Nina Papavasiliou (Addgene plasmid \# 15925), was digested with XhoI and EcoRI restriction enzymes to remove AID gene, and repaired by Klenow fragment. The constructs harbouring the U6 promoter-gRNA-gRNA scaffoldEF1 $\alpha$ promoter-SpCas9-NLS-flag-P2A-Puro were obtained from LentiCRISPR v2 vector, and repaired by Klenow fragment. By ligating those two constructs, we generated RetroCRISPR v1 plasmid (Supplementary Fig. 3a). Since smaller size of plasmid is more efficient to produce retroviral particles, we decided to make a RetroCRISPR v2 plasmid. The construct harbouring BamHI-P2A-GFP-ClaI was PCR amplified using pMSCVgfp:AID as a template with forward primer: $5^{\prime}$-TAA GGGATCCGGCGCAACAAACTTCTCTCTGCTGAAACAAGCCGGAGATGT CGAAGAGAATCCTGGA CCGGTGAGCAAGGGCGAGGAGCTGTTC-3' and reverse primer: 5'-TAAGATCGATGGCCGCTTTACTTGTACAGCTCGTCC ATGC-3' (BamHI and ClaI sites are underlined). To generate RetroCRISPR v2 plasmid, PCR products were cloned into RetroCRISPR v1 plasmid digested with BamHI and ClaI restriction enzymes (Supplementary Fig. 3b).

$\mathrm{PI} 3 \mathrm{~K} \delta^{\mathrm{E} 1021 \mathrm{~K}}$ construct cloned in GFP-reporter MIGR1 retroviral vector was a kind gift from Dr Klaus Okkenhaug (The Babraham Institute, Cambridge, UK). As a control, we used GFP-reporter MIGR1 plasmid, which was a gift from Warren Pear (Addgene plasmid \# 27490).

Lenti- and Retro-viral particle productions. HEK293FT cells (Invitrogen), Phoenix-ECO cells (ATCC), and GP2-293 packaging cells (Clontech) were maintained in DMEM supplemented with $10 \%$ fetal bovine serum (FBS; ATLANTA), 100 units per $\mathrm{ml}$ penicillin-streptomycin (P/S; Corning), and $2 \mathrm{mM} \mathrm{L}$-Glutamine (L-Glu; Corning). Cells were cultured at $37^{\circ} \mathrm{C}$ in $5 \% \mathrm{CO}_{2}$ atmosphere. The cell lines were tested and resulted negative for Mycoplasma contamination.
To generate lentiviral particle, $5.5 \times 10^{6}$ HEK293FT cells were plated per $10-\mathrm{cm}$ dish. The following day, cells were transfected by calcium phosphate transfection method (CalPhos Mammalian Transfection Kit; Clontech) with $7.2 \mu \mathrm{g}$ of lentiCRISPR plasmid, $3.6 \mu \mathrm{g}$ of pMD2.G (Addgene plasmid \#12259), $3.6 \mu \mathrm{g}$ of pRSV-Rev (Addgene plasmid \#12253) and $3.6 \mu \mathrm{g}$ of pMDLg/pRRE (Addgene plasmid \#12251). The media was changed $8 \mathrm{~h}$ post-transfection. The viral supernatant was collected $48 \mathrm{~h}$ post-transfection, passed through a $0.45-\mu \mathrm{m}$ filter, pooled and used either fresh or snap frozen.

To generate retroviral particle for mouse B cells, $3.5 \times 10^{6}$ Phoenix-ECO cells were plated per $10-\mathrm{cm}$ dish. The following day, cells were transfected by calcium phosphate transfection method (CalPhos Mammalian Transfection Kit) with $10 \mu \mathrm{g}$ of retroviral plasmid and $5 \mu \mathrm{g}$ of pCL-Eco retrovirus packaging plasmid. The media was changed $8 \mathrm{~h}$ post-transfection. The viral supernatant was collected $48 \mathrm{~h}$ post-transfection, passed through a $0.45-\mu \mathrm{m}$ filter, pooled and used either fresh or snap frozen.

To generate retroviral particle for human cells, $3.5 \times 10^{6}$ GP2-293 packaging cells were plated per $10-\mathrm{cm}$ dish. The following day, cells were transfected by Xfect transfection reagent (Clontech) with $10 \mu \mathrm{g}$ of retroviral plasmid and $5 \mu \mathrm{g}$ of pCMV-VSV-G (Addgene plasmid \#8454) retrovirus envelop plasmid. The media was changed $4 \mathrm{~h}$ post-transfection. The viral supernatant was collected $48 \mathrm{~h}$ post-transfection, passed through a $0.45-\mu \mathrm{m}$ filter, pooled and used either fresh or snap frozen.

Cell cultures, transduction and puromycin selection. Mouse fibroblast cells immortalized with SV-40 LT (pBABE-puro SV40 LT; Addgene plasmid \# 13970) were maintained in DMEM supplemented with $10 \% \mathrm{FBS}, 100$ units per $\mathrm{ml} \mathrm{P} / \mathrm{S}$, and $2 \mathrm{mM} \mathrm{L-Glu}$. Cells were cultured at $37^{\circ} \mathrm{C}$ in $5 \% \mathrm{CO}_{2}$ atmosphere. For transduction, $2 \times 10^{4}$ cells were plated into six-well plates. The following day, cells were transduced with viral supernatant supplemented with $6 \mu \mathrm{g} \mathrm{ml}^{-1}$ polybrene. The viral supernatant was exchanged for fresh medium $6 \mathrm{~h}$ later. After 2 days, cells were treated with $6 \mu \mathrm{g} \mathrm{ml}^{-1}$ of puromycin to select resistant cells until non-infected cells were completely dead.

Naive B cells were separated from total spleen cell suspensions using anti-CD43 magnetic microbeads (Miltenyi). The CD43-negative fraction was cultured with anti-CD40 antibody ( $1 \mu \mathrm{g} \mathrm{ml}^{-1}$; eBioscience) and IL-4 (20 $\mathrm{ng} \mathrm{ml}^{-1}$; PeproTech) for 4 days. Retrovirus infection was performed $24 \mathrm{~h}$ post-activation. Activated-B cells were transduced with viral supernatant supplemented with $6 \mu \mathrm{g} \mathrm{ml}{ }^{-1}$ polybrene. The viral supernatant was exchanged for fresh medium containing anti-CD40 antibody and IL-4 $6 \mathrm{~h}$ later.

Hybridomas were generated by fusion between anti-CD40 and IL-4-stimulated B cells from 129/SvJ mice and NS-1 fusion partner myeloma cells on day 4 and were recovered after 7 days selection with $1 \times$ Hypoxanthine Aminopterin Thymidine (HAT) medium. Single clones from each well were picked and screened by ELISA on their supernatants with IgM and IgG $_{1}$ capturing and revealing antibodies (Southern Biotech). Only clones that were single positive for one of the two antibody classes were used in this study. Hybridomas were cultured in RPMI 1640 medium GlutaMax (Invitrogen) supplemented with $15 \%$ FBS and 100 units per $\mathrm{ml} \mathrm{P/S}$. Hybridomas were maintained at $37^{\circ} \mathrm{C}$ in $5 \% \mathrm{CO}_{2}$ atmosphere. For transduction, $2 \times 10^{5}$ cells were plated into six-well plates and transduced with viral supernatant supplemented with $6 \mu \mathrm{g} \mathrm{ml}^{-1}$ polybrene. The viral supernatant was exchanged for fresh medium $6 \mathrm{~h}$ later. After 2 days, cells were treated with $3 \mu \mathrm{g} \mathrm{ml}^{-1}$ of puromycin to select resistant cells until non-infected cells were completely dead.

Mantle cell lymphoma (JEKO-1, GRANTA-519, MAVER-1 and MINO from DSMZ; Z-138 from ATCC; UPN-1 and UPN-2 from Dr Alberto Zamo' (University of Verona, Italy), Burkitt lymphoma (BL-41 and BJAB from DSMZ), and chronic lymphocytic leukaemia (MEC-1 from DSMZ) cell lines were used in this study. All human lymphomas were cultured and maintained in RPMI 1640 medium supplemented with $10 \% \mathrm{FBS}, 100$ units per $\mathrm{ml}^{-1} \mathrm{P} / \mathrm{S}$, and $2 \mathrm{mM} \mathrm{L}-\mathrm{Glu}$. All cell lines were cultured at $37^{\circ} \mathrm{C}$ in $5 \% \mathrm{CO}_{2}$ atmosphere. The cell lines all tested negative for Mycoplasma contamination. For transduction, $2 \times 10^{5}$ cells were plated into six-well plates and transduced with viral supernatant supplemented with $6 \mu \mathrm{g} \mathrm{ml}^{-1}$ polybrene. The viral supernatant was exchanged for fresh medium $6 \mathrm{~h}$ later. After 2 days, cell lines were treated with $0.2 \mu \mathrm{g} \mathrm{ml}^{-1}$ of puromycin to select resistant cells until non-infected cells were completely dead. For PI3K $\delta^{\text {E1021K }}$ rescue experiments, JEKO-1 cells were first transduced with lentiviruses to induce deletion between $S \mu$ and $S \gamma 3$, cultivated for 5 days and then transduced with GFP-reporter PI3K $\delta^{\mathrm{E} 1021 \mathrm{~K}}$ or control MIGR1 retrovirus.

Genomic DNA isolation, PCR and sequencing analysis. Mouse fibroblast, hybridomas and JEKO-1 cells were transduced with lentiviruses, selected with puromycin and collected after 5 days of transduction. Genomic DNA was extracted using Rapid lysis buffer (100 mM Tris- $\mathrm{HCl}$ pH8.0, $200 \mathrm{mM} \mathrm{NaCl}, 5 \mathrm{mM}$ EDTA, $0.2 \%$ SDS) with $100 \mu \mathrm{g} \mathrm{ml}^{-1}$ Proteinase $\mathrm{K}$ by incubating at $56^{\circ} \mathrm{C}$ overnight. Genomic DNA was precipitated in one volume isopropanol, and the DNA pellet was resuspended in $10 \mathrm{mM}$ Tris- $\mathrm{HCl}(\mathrm{pH} 8.0)$. Primers used for PCR amplifications to detect deletions, inversions, and excision circles from mouse fibroblasts, hybrodomas or JEKO-1 cells are listed in Supplementary Table 3. PCR products were gel purified and cloned using pGEM-T easy vector system (Promega). Mutations were identified by Sanger sequencing. Uncropped gel images are shown in Supplementary Figs 14 and 15. 
Surveyor assay. The genomic region flanking the CRISPR target sites was PCR amplified (Surveyor primers are listed in Supplementary Table 3), and products were purified using PCR purification kit (QIAGEN) following the manufacturer's protocol. A total of $400 \mathrm{ng}$ of the purified PCR products were mixed with $2 \mu \mathrm{l} 10 \times$ Taq DNA Polymerase PCR buffer (Life Technologies) and ultrapure water to a final volume of $20 \mu \mathrm{l}$, and subjected to a reannealing process to enable heteroduplex formation: $95^{\circ} \mathrm{C}$ for $10 \mathrm{~min}, 95^{\circ} \mathrm{C}$ to $85^{\circ} \mathrm{C}$ ramping at $-2{ }^{\circ} \mathrm{C}$ per second, $85^{\circ} \mathrm{C}$ to $25^{\circ} \mathrm{C}$ at $-0.25^{\circ} \mathrm{C}$ per second, and $25^{\circ} \mathrm{C}$ hold for $1 \mathrm{~min}$. After reannealing, products were treated with SURVEYOR nuclease and SURVEYOR enhancer S (Transgenomics) for $1 \mathrm{~h}$ at $42^{\circ} \mathrm{C}$, and analysed on 2\% high-resolution agarose gel (A4718, Sigma Aldrich). Gels were stained with ethidium bromide (Sigma Aldrich) and imaged with a Gel Doc gel imaging system (Bio-rad). Quantification was based on relative band intensities. Indel percentage was determined by the formula, $100 \times(1-(1-(b+c) /(a+b+c)) 1 / 2)$, where $\mathrm{a}$ is the integrated intensity of the undigested PCR product, and $b$ and $c$ are the integrated intensities of each cleavage products

Flow cytometry. Mouse B cells and hybridomas were stained with PE-conjugated anti-IgG ${ }_{1}$ antibody (Clone A85-1, 550083, BD Pharmingen, 1:100 dilution) or APC-conjugated anti-IgM antibody (17-5790-82, eBioscience, 1:100 dilution) for $30 \mathrm{~min}$ on ice, and analysed using a FACSVerse flow cytometer (BD Biosciences). $\mathrm{IgG}_{1}^{+}$cells were gated on GFP. Data were analysed by FlowJo software.

Human lymphoma cells were co-stained with APC-conjugated anti-CD19 (Clone 4G7-2E3, FAB4867A, R\&D System, 1:100 dilution) and either FITCconjugated anti-IgM (AHI1608, MyBioSource, 1:100 dilution) or FITC-conjugated anti-IgG (AHI1308, MyBioSource, 1:100 dilution) or FITC-conjugated anti-IgA antibodies (AHI1108, MyBioSource, 1:100 dilution) for $30 \mathrm{~min}$ on ice to detect IgG or IgA switching, respectively. For simultaneous switching, JEKO-1 cells were transduced with three different lentiviruses indicated in Supplementary Fig. 9. Cells were co-stained with PE-conjugated anti-IgG (AHI1307, MyBioSource) and FITCconjugated anti-IgA antibodies (MyBioSource) for $30 \mathrm{~min}$ on ice. To detect sequential switching, cells were stained with the three following combinations: FITC-conjugated anti-IgM and PE-conjugated anti-IgG, FITC-conjugated anti-IgA and PE-conjugated anti-IgG, or PE-conjugated anti-IgM (AHI1607, MyBioScience, 1:100 dilution) and FITC-conjugated anti-IgA antibodies for $30 \mathrm{~min}$ on ice. Cells were analysed using a FACSVerse flow cytometer (BD biosciences). Data were analysed by FlowJo software (FlowJo).

Western blot analysis. $\mathrm{IgG}_{1^{-}}$or $\mathrm{Fab}^{\prime}$ fragment-producing hybridomas were cultured in six-well plates $\left(3 \times 10^{6}\right.$ cells in $2 \mathrm{ml}$ of HBSS). After $24 \mathrm{~h}$, supernatants were collected and centrifuged to remove dead cells. For non-reducing condition, supernatants were mixed with loading buffer without reducing reagents. For reducing condition, supernatants were mixed with loading buffer containing $\beta$-mercaptoethanol and boiled at $95^{\circ} \mathrm{C}$ for $5 \mathrm{~min}$. In both conditions, samples were loaded on 4-15\% Mini-PROTEIN TGX gels (BIO-RAD), transferred on nitrocellulose membrane (GE Healthcare), blocked with 5\% Skim milk (BIO-RAD), incubated with Rat monoclonal anti-mouse kappa-light chain (HRP) (clone H139-52.1, ab99632, Abcam, 1:5,000 dilution) or Goat polyclonal anti-mouse IgG-H\&L chain (HRP) (NA931V, GE Healthcare, 1:5,000 dilution), and developed with ECL solution (GE Healthcare). Uncropped western blot images are shown in Supplementary Figs 16 and 17.

Statistical analysis. The statistical analysis represented mean \pm s.d. from three or more independent experiments. Data were analysed by unpaired $t$-test for group differences and by two-way analysis of variance analysis of variance for condition and group differences together using GraphPad Prism 6 software; ${ }^{*} P<0.01$, ${ }^{* * *} P<0.001$

\section{References}

1. Gostissa, M., Alt, F. W. \& Chiarle, R. Mechanisms that promote and suppress chromosomal translocations in lymphocytes. Annu. Rev. Immunol. 29, 319-350 (2011).

2. Jung, D., Giallourakis, C., Mostoslavsky, R. \& Alt, F. W. Mechanism and control of $\mathrm{V}(\mathrm{D}) \mathrm{J}$ recombination at the immunoglobulin heavy chain locus. Annu. Rev. Immunol. 24, 541-570 (2006)

3. Stavnezer, J., Guikema, J. E. J. \& Schrader, C. E. Mechanism and regulation of class switch recombination. Annu. Rev. Immunol. 26, 261-292 (2008).

4. Boboila, C., Alt, F. W. \& Schwer, B. Classical and alternative end-joining pathways for repair of lymphocyte-specific and general DNA double-strand breaks. Adv. Immunol. 116, 1-49 (2012).

5. Gostissa, M. et al. IgH class switching exploits a general property of two DNA breaks to be joined in cis over long chromosomal distances. Proc. Natl Acad. Sci. USA 111, 2644-2649 (2014).

6. Zarrin, A. A. et al. Antibody class switching mediated by yeast endonucleasegenerated DNA breaks. Science 315, 377-381 (2007).

7. Hsu, P. D., Lander, E. S. \& Zhang, F. Development and applications of CRISPRCas9 for genome engineering. Cell 157, 1262-1278 (2014)

8. Shalem, O., Sanjana, N. E. \& Zhang, F. High-throughput functional genomics using CRISPR-Cas9. Nat. Rev. Genet. 16, 299-311 (2015).
9. Doudna, J. A. \& Charpentier, E. Genome editing. The new frontier of genome engineering with CRISPR-Cas9. Science 346, 1258096 (2014).

10. O'Connell, M. R. et al. Programmable RNA recognition and cleavage by CRISPR/Cas9. Nature 516, 263-266 (2014).

11. Choi, P. S. \& Meyerson, M. Targeted genomic rearrangements using CRISPR/ Cas technology. Nat. Commun. 5, 3728 (2014).

12. Torres, R. et al. Engineering human tumour-associated chromosomal translocations with the RNA-guided CRISPR-Cas9 system. Nat. Commun. 5, 3964 (2014).

13. Blasco, R. B. et al. Simple and rapid in vivo generation of chromosomal rearrangements using CRISPR/Cas9 technology. Cell Rep. 9, 1219-1227 (2014).

14. Maddalo, D. et al. In vivo engineering of oncogenic chromosomal rearrangements with the CRISPR/Cas9 system. Nature 516, 423-427 (2014).

15. Chiarle, R. et al. Genome-wide translocation sequencing reveals mechanisms of chromosome breaks and rearrangements in B cells. Cell 147, 107-119 (2011).

16. Carter, P. J. Potent antibody therapeutics by design. Nat. Rev. Immunol. 6, 343-357 (2006).

17. Srinivasan, L. et al. PI3 kinase signals BCR-dependent mature B cell survival. Cell 139, 573-586 (2009)

18. Kraus, M., Alimzhanov, M. B., Rajewsky, N. \& Rajewsky, K. Survival of resting mature B lymphocytes depends on BCR signaling via the Igalpha/beta heterodimer. Cell 117, 787-800 (2004).

19. Young, R. M. \& Staudt, L. M. Targeting pathological B cell receptor signalling in lymphoid malignancies. Nat. Rev. Drug Discov. 12, 229-243 (2013).

20. Angulo, I. et al. Phosphoinositide 3-kinase delta gene mutation predisposes to respiratory infection and airway damage. Science 342, 866-871 (2013).

21. Lucas, C. L. et al. Dominant-activating germline mutations in the gene encoding the $\mathrm{PI}(3) \mathrm{K}$ catalytic subunit p110delta result in $\mathrm{T}$ cell senescence and human immunodeficiency. Nat. Immunol. 15, 88-97 (2014).

22. Filpula, D. Antibody engineering and modification technologies. Biomol. Eng. 24, 201-215 (2007)

23. Feige, M. J., Hendershot, L. M. \& Buchner, J. How antibodies fold. Trends Biochem. Sci. 35, 189-198 (2010).

24. Couture, M. L. \& Heath, C. A. Relationship between loss of heavy chains and the appearance of nonproducing hybridomas. Biotechnol. Bioeng. 47, 270-275 (1995).

25. Alt, F. W., Zhang, Y., Meng, F. L., Guo, C. \& Schwer, B. Mechanisms of programmed DNA lesions and genomic instability in the immune system. Cell 152, 417-429 (2013).

26. Jinek, M. et al. A programmable dual-RNA-guided DNA endonuclease in adaptive bacterial immunity. Science 337, 816-821 (2012).

27. Chiarle, R. Translocations in normal B cells and cancers: insights from new technical approaches. Adv. Immunol. 117, 39-71 (2013).

28. Hakim, O. et al. DNA damage defines sites of recurrent chromosomal translocations in B lymphocytes. Nature 484, 69-74 (2012).

29. Sanjana, N. E., Shalem, O. \& Zhang, F. Improved vectors and genome-wide libraries for CRISPR screening. Nat. Methods 11, 783-784 (2014).

30. Ran, F. A. et al. In vivo genome editing using Staphylococcus aureus Cas9. Nature 520, 186-191 (2015).

31. Deonarain, M. P., Yahioglu, G., Stamati, I. \& Marklew, J. Emerging formats for next-generation antibody drug conjugates. Expert Opin Drug Discov. 10, 463-481 (2015).

32. Horiuchi, K. et al. Analysis of somatic hypermutations in the IgM switch region in human B cells. J. Allergy Clin. Immunol. 134, 411-419 (2014).

33. Byrd, J. C. et al. Targeting BTK with ibrutinib in relapsed chronic lymphocytic leukemia. N. Engl. J. Med. 369, 32-42 (2013).

34. Wang, M. L. et al. Targeting BTK with ibrutinib in relapsed or refractory mantle-cell lymphoma. N. Engl. J. Med. 369, 507-516 (2013).

35. Furman, R. R. et al. Idelalisib and rituximab in relapsed chronic lymphocytic leukemia. N. Engl. J. Med. 370, 997-1007 (2014).

36. Gopal, A. K. et al. PI3Kdelta inhibition by idelalisib in patients with relapsed indolent lymphoma. N. Engl. J. Med. 370, 1008-1018 (2014).

37. Wilson, W. H. et al. Targeting B cell receptor signaling with ibrutinib in diffuse large B cell lymphoma. Nat. Med. 21, 922-926 (2015).

38. Hamadani, M., Balasubramanian, S. \& Hari, P. N. Ibrutinib in refractory classic Hodgkin's lymphoma. N. Engl. J. Med. 373, 1381-1382 (2015).

39. Fruman, D. A. \& Cantley, L. C. Idelalisib--a PI3Kdelta inhibitor for B-cell cancers. N. Engl. J. Med. 370, 1061-1062 (2014).

40. Byrd, J. C. et al. Acalabrutinib (ACP-196) in Relapsed Chronic Lymphocytic Leukemia. N. Engl. J. Med. 374, 323-332 (2015).

\section{Acknowledgements}

We thank Dr Klaus Okkenhaug and Dr Fabien Garcon (The Babraham Institute, UK) for kindly providing plasmids with control and mutated $\mathrm{PI} 3 \mathrm{~K} \delta^{\mathrm{E} 1021 \mathrm{~K}}$ constructs. The work has been supported by grants AIRC MFAG to M.C.; Bando Giovani Ricercatori 2009-GR 1603126 to M.C.; FP7 ERC-2009-StG (Proposal No. 242965-'Lunely') to R.C.; Associazione Italiana per la Ricerca sul Cancro (AIRC) grant IG-12023 to RC; Koch Institute/DFCC Bridge Project Fund to R.C.; Ellison Foundation Boston to R.C.; 
Worldwide Cancer Research (former AICR) grant 12-0216 to R.C.; and R01 CA19670301 to R.C.

\section{Author contributions}

T.-C.C. designed and performed experiments, analysed and interpreted the data, and wrote the manuscript. M.C. contributed essential reagents. R.C. conceived and designed the experiments, analysed the data and wrote the manuscript.

\section{Additional information}

Supplementary Information accompanies this paper at http://www.nature.com/ naturecommunications

Competing financial interests: The authors declare no competing financial interests.
Reprints and permission information is available online at http://npg.nature.com/ reprintsandpermissions/

How to cite this article: Cheong, T.-C. et al. Editing of mouse and human immunoglobulin genes by CRISPR-Cas9 system. Nat. Commun. 7:10934 doi: $10.1038 /$ ncomms10934 (2016).

(c) (i) This work is licensed under a Creative Commons Attribution 4.0 International License. The images or other third party material in this article are included in the article's Creative Commons license, unless indicated otherwise in the credit line; if the material is not included under the Creative Commons license, users will need to obtain permission from the license holder to reproduce the material. To view a copy of this license, visit http://creativecommons.org/licenses/by/4.0/ 